\title{
ГЕНДЕР АДРЕСАТА КАК ФАКТОР КОММУНИКАЦИИ
}

\section{THE RECIPIENT'S GENDER AS A FACTOR OF COMMUNICATION}

\section{E. Krivosheeva}

Summary: This article is devoted to the study of the addressee's gender as a factor in everyday communication.

In the course of the research, the texts of everyday communication were analyzed, and the ways and means of gender addressing were analyzed, which the communicant can use both when generating speech and when perceiving it.

A communicative-pragmatic approach was used in the study of linguistic material. The results of the study are the analysis of examples of everyday speech.

Keywords: communication, stereotype, gender, communicative approach, communicant.

\section{Кривошеева Елена Николаевна \\ Стариий преподаватель, РУДН (МОСКВА) \\ krivosheeva.elena.1969@mail.ru}

Аннотация: Данная статья посвящена изучению гендера адресата как фактора в обиходной коммуникации.

В процессе исследования анализу были подвергнуты тексты обиходной коммуникации, были проанализированы способы и средства гендерной адресации. Коммуникант может пользоваться ими как при порождении речи, так и при ее восприятии.

При исследовании лингвистического материала применялся коммуникативный подход. Результатами исследования является анализ примеров обиходно-бытовой речи.

Ключевые слова: коммуникация, стереотип, гендер, коммуникативный подход, коммуникант.

\section{Введение}

И сследование посвящено изучению гендера адресата как фактора в обиходной коммуникации, в современных текстах общения.

Объектом исследования являются высказывания/ дискурсы / тексты в процессе обиходной коммуникации.

Предметом исследования являются способы и средства гендерной адресации высказывания / дискурса/ текста, которыми пользуется коммуникант при построении высказывания.

Цель работы: исследовать аспекты воздействия адресанта на адресата, определяемые гендером адресата.

\section{Методы и материалы}

Современная лингвистика ставит в центр внимания человека, отраженного в языке и использующего язык. В лингвистике существует представление о человеке, способном к коммуникации, как о языковой личности: это структура личности, общая для всех членов общества и формирующаяся под воздействием социальной среды [3].

Языковая личность проявляется в дискурсе, понимаемом как «речь, погруженная в жизнь» [1].

Дискурс - это не только связная речь как процесс, но и ее включенность в коммуникативную ситуацию, выступающую как условие возникновения именно такой, а не иной связной речи. В дискурсе отражается личность адресанта и адресата во всем многообразии его характеристик, в том числе гендерных.

«Адресат - это та фигура, которая определяет природу общения как коммуникативного взаимодействия» (2). Вслед за Н.И. Формановской мы различаем три функции адресата как субъекта общения:

1. адресат как мысленный образ в речевом сознании автора, заставляющий его именно так выбирать языковые средства и строить речевое произведение;

2. адресат как субъект восприятия и понимания дискурса/текста;

3. адресат как субъект реакции на дискурс/текст, вступающий в тот или иной ответ (эмоциями, речью, отношением, действием и т.д.).

В статье рассматривается прежде всего первая функция адресата, то есть мысленный образ адресата в сознании автора высказывания, поскольку именно она определяет структуру и специфику речевого произведения автора. При этом для целей данной работы избрана лишь одна характеристика адресата - гендерная.

Изучение специфики речи мужчин и женщин требует создания комплексной модели их речевого поведения.

В статье предлагается концепция гендерных маркеров как фрагментов высказывания/ дискурса/ текста, способных отличить мужчин (по полу и/или гендеру) от 
женщин (по полу и/или гендеру).

Маркер пола или гендера может появиться в любой на любом этапе высказывания, при этом он будет интерпретироваться как показатель пола/гендера адресанта (зона первого лица), адресата (зона второго лица) либо того, кто не участвует в общении. До сих пор вопрос о различиях в коммуникативном поведении мужчин и женщин решался преимущественно «в зоне адресанта»: обсуждалось, чем отличается речевое поведение лиц разного пола или гендера. Однако различия можно обнаружить и в том, как говорят с мужчинами и женщинами, и как говорят о мужчинах и женщинах.

В статье выделяются следующие группы гендерных маркеров: фонетические (высота тона, тембр голоса, интонирование, паузы, логические выделения), морфологические (употребление слов и форм), лексическо- грамматические (употребление слов, называющих мужчину или женщину), экспрессивно-стилистические (преимущественное употребление слов и конструкций, более характерных для мужской или женской коммуникации). Вообще, стереотипно к «мужским» словам относятся «грубые» слова», короткие высказывания и др., а к «женским» - слова и конструкции высокой стилистической окраски, типичные для экзальтированной, восторженной речи, диминутивы и мн. др.; тематические (употребление слов, связанных со стереотипно «мужскими» и «женскими» темами).

В работе уделяется особое внимание стереотипным маркеры: адресация высказывания/дискурса/текста с опорой на стереотипные представления о том, что характерно для женщины или мужчины. Эти маркеры во многом отражают психологию нашей речи, являются гендерными признака пола в построении речи и текста.

Предложенная модель описания применяется для анализа обиходно-бытового общения. Обиходно-бытовое повседневное общение - это речевые взаимодействия, в которые человек включен каждый день; они характеризуются непринужденностью, неподготовленностью, непосредственным участием коммуникантов в коммуникативном акте.

В контексте проблемы гендерной адресации наибольшее значение имеет то, что говорящий в обиходной коммуникации обычно знает, кто именно его адресат, и указывает его непосредственно, с помощью обращений, местоимений и т.д. Поэтому языковые - лексические и грамматические - маркеры нередко становятся избыточными, но все же появляются постольку, поскольку этого требует коммуникативная задача адресанта и грамматический строй фразы: «Олег! А я просто сам тормознул, я же забыл про этот телесон! У меня из башки вылетело, блин! Ну, вот вспомнил? Вспомнил, да?» (3an. у. p., $M-27$ лет).

Особый интерес в этом типе общения представляют тематические маркеры. В обиходном общении выбор тем может определяться разными факторами, но прежде всего он связан с представлениями говорящего о том, что интересно собеседнику. Гендерно маркированной можно считать тему, которая возникает преимущественно в диалогах с представителем одного гендера и при этом слабо представлена в общении с представителем другого гендера.

Представления о коммуникации женщин закрепились в стереотипах, которые отражены в таких устойчивых сочетаниях, как бабьи сплетни, бабьи разговоры, общение мужчин представлено в культурном сознании в таких сочетаниях, как мужской разговор, поговорить по-мужски. И если в характеристиках общения женщин закрепились отрицательные коннотации, то сочетания, характеризующие мужское общение, скорее несут положительные оценки. Вряд ли можно утверждать, что сплетня и болтовня - исключительно женский жанр. Однако общение мужчин, в случае если оно имеет малосодержательный характер или представляет собой обсуждение жизни третьих лиц, также может получить название бабьей сплетни или женской болтовни.

Материал анализируемых коммуникативных эпизодов дает возможность утверждать, что в сложившейся культурной ситуации вряд ли существует тема, которую не могли бы обсуждать мужчины или женщины, но можно говорить о гендерных предпочтениях. Наблюдения показывают, что женщины в непринужденной беседе предпочитают обмениваться мнениями о внешнем виде, здоровье, покупках, об одежде, о детях, о мужчинах, о третьих лицах и мн. др.

Обсуждение с адресатом покупок - одна из самых популярных женских тем: «Я купила себе шелковую белую блузку с оба-а-лденным огромным атласным воротником» (3an. у. р., Ж - 29 лет). Мечты об одежде, которыми уместно поделиться с адресатом, мысли об одежде, обсуждение, что с чем следует носить, советы, как носить - неотъемлемые темы для беседы у женщин: «Не знаю, что делать с белым свитером, я его никогда носить уже не буду» (3an. у. p., Ж-26 лет). При обсуждении этой темы адресатом, как правило, становится женщина.

Женщины часто советуются с адресатом о внешнем виде, о здоровье, похудении, и, в связи с этим, о том, как выглядеть лучше. Устойчивые выражения «секреты похудения», «рецепты красоты» относятся к женскому арсеналу:

Ж1 Как вы хорошо выглядите! В чем секрет?

ж2 Не ем после шести и зарядка каждый день! (3an. у. р., Ж1-49л., Ж2-55л.). 
Тема красоты и здоровья интересует, конечно, и мужчин, и женщин, с той оговоркой, что к женщине практически всегда, в любом возрасте, можно адресоваться с темой красоты, внешнего вида, мужчины же часто не склонны обсуждать эти темы, а тема здоровья преимущественно появляется с возрастом.

Тема мужчин является гендерно маркированной для женщин. При этом обсуждаются с адресатом либо личные отношения с мужчиной, либо качества мужчин (внешность, поведение, характер, положение в обществе и т.д.), являющиеся немаловажными для выстраивания отношений: «Я должна признаться, девочки, что мне начинает нравиться Женя, девочки, что мне делать?» (3an. у. p., $Ж-22$ года).

Тема обсуждения жизни третьих лиц часто становится важной в общении женщин, что и порождает общее представление о том, что женщины «сплетничают»: «Знаешь, Тань, мне так нравится, как меняются мои ровесники, а вот она не меняется» (3an. у. р., Ж - 32 года). Близкой к обсуждению жизни третьих лиц может быть тема «жизнь замечательных людей».

Наблюдения за коммуникацией мужчин показывают, что мужчины предпочитают говорить с адресатами о технике, оружии, машинах, женщинах, спорте, хобби, темой могут быть спорные исторические и политические вопросы.

Диалоги о технике, техническом прогрессе преимущественно мужские. Даже не имея к технике профессионального отношения, мужчины часто имеют любительские представления о различного рода устройствах и новинках: «Смотри, Володь, какие штуки купил: клавиатура и мышь инфракрасная, можно, сидя на диване, на расстоянии работать или кино смотреть» (3an. у. р., $M$ -32 года).

Обсуждение с адресатом техники тесно связано с миром увлечений, хобби мужчин. Мотоциклы и рыболовные принадлежности, оружие и компьютерные игры, музыка и спорт - вот далеко не полный список обсуждаемых тем, совмещающих вопросы техники и увлечений. Вопросы увлечений обсуждаются нередко не только в практическом плане личных достижений и намерений, но с намерением узнать мнение адресата, получить его совет.

Тема женщин является в мужском общении гендерно маркированной. Обсуждаются прежде всего внешность и поведение женщин, личные качества женщины затрагиваются лишь в той мере, в которой они влияют на жизнь мужчины:

М1 А Оксанка ничего, красивая, только к ней не подойдешь. Скажи?
M2 Ты рот-то не разевай, у нее жених есть (3an. у. p., M1 - 25 лет, M2 - 27 лет).

Наблюдения показали, что мужчины могут обсуждать с адресатом третьих лиц, отношения и моменты жизни третьих лиц, как рабочие, так и личные отношения людей: «Басовы разбежались, он женился на какой-то сотруднице, она тоже вышла замуж за программиста, парня моложе ее...» (3an. у. р., M - 30 лет).

Способом выявления гендерно маркированной темы может быть гендерный конфликт. Смешанные коммуникации нередко приводят к тому, что преобладание гендерно маркированных тем может вызвать протест у адресата-носителя другого гендера. Таким образом, в повседневном обиходном общении многие темы обнаруживают гендерную маркированность, проявляющуюся в коммуникативных предпочтениях представителей того или иного гендера, большей частоте обсуждений с адресатом, в предпочтениях тех или иных тем, и в то же время в возникновении гендерных разногласий в ситуациях смешанного общения.

В русской культуре есть фактор воспитания, предписывающий, что женщина должна быть более сдержанна в проявлении «активных» негативных эмоций, чем мужчина. Такие эмоции, как гнев, раздражение, и экспрессивы, их выражающие - сниженная лексика, нецензурные слова прерогатива мужчины. С другой стороны, мужчины более ограничены в адресации сильных «пассивных» эмоций, как отрицательных, так и положительных: боли, обиды, печали, восторга. Ср. типичные указания мальчику: «Не плачь, тыже не девочка»; «Расчувствовался, как девчонка». [6]

В ходе работы был отобран ряд текстов, в которых мужчины и женщины адресуют свои эмоции, при этом производилась количественная оценка соответствующих фрагментов коммуникации. Наблюдения показали, что женщины не только чаще проявляют эмоции, но и адресуют их собеседницам в расчете на сочувствие, особенно сильные эмоции - раздражение, восхищение адресатом или предметом его личной сферы, чаще оценивают предмет разговора:

Ж Ой, я не могу, какой дом шикарный, я не могу, я пошла отсюда, я не могу смотреть. Марин, меня сейчас жаба задушит. Я тоже хочу вот сюда! Как хорошо! Я вот сюда хочу. (Зап. у. р., Ж- 25 лет).

В повседневном обиходно-бытовом общении с адресатом мужчины не столь эмоциональны, меньше оценивают, реже характеризуют, дают комментарии по поводу тех или иных объектов коммуникации. Часто комментарии и оценки оказываются стилистически нейтральными: хорошо-плохо-нормально:

М1 Нормально, нормально, похож.

М2 Нормально, нормально, отлично, отлично (3an. у. p., $M 1-24$ г., $M 2-29$ л.). 
Отдельно следует рассматривать адресацию с эмоциями раздражения, гнева, возмущения, здесь мужчины часто очень экспрессивны, более того, гендерный стереотип оставляет право на обмен сниженной лексикой, грубостью за мужчинами. [4]

Исследование показало, что коммуникативное поведение мужчин и женщин по отношению к адресату различается в степени эмоциональности; однако это различие описывается в терминах не «наличие/отсутствие экспрессивности», а «большая/меньшая экспрессивность». Например, грубая адресованная речь не оценивается как однозначно «мужская» или «предназначенная мужчине» - хотя гендерный стереотип оценит женщину, говорящую грубо, как «мужичку»; точно так же излишне возвышенная, экзальтированная, эмоциональная речь не воспринимается как сугубо женская - хотя гендерный стереотип предъявит мужчине-автору такого высказывания претензию, что он ведет себя, «как баба».

Любой тип гендерных маркеров в адресации при обиходной коммуникации тем важнее, чем меньше знакомы коммуниканты, чем более «неопределенны» они друг для друга. Если возникает регулярная коммуникация, значимость общих гендерных маркеров постепенно уменьшается, уступая место «персональным маркерам». Именно благодаря обиходному опыту взаимодействия с представителями разных полов/гендеров мы приобретаем знания о том, как можно привлечь внимание мужчин и женщин, как выстроить общение с ними.[5]

Грамматический мужской род слов, обозначающих адресата, не является абсолютным маркером, а может быть гендерно нейтральным: Пустырник форте. Стань хозяином своих эмоций! Эвалар (Телесемь, 2007, 10-16 дек.); Банк Стройкредит. Как получить до 12\% годовых в новом году? Вклад новогодний. Подарок каждому вкладчику! (7Д, 2007, №50). В использовании такого «нейтрального» рода может быть заключен замысел авторов, не желающих гендерно ограничивать адресацию.

Особенности речевого стиля мужчин и женщин проявляется на двух уровнях: речевого поведения и речи. Например, мужчины чаще перебивают, более категоричны, стремятся управлять тематикой диалога. Существенно, что в отличие от распространенного мнения, мужчины говорят больше, чем женщины. Мужские предложения, как правило, короче женских. Мужчины в целом гораздо чаще употребляют абстрактные существительные, а женщины - конкретные (в том числе имена собственные). Мужчины чаще используют существительные (в основном, конкретные) и прилагательные, в то время как женщины употребляют больше глаголов. Мужчины употребляют больше относительных прилагательных, а женщины - качественных. Мужчины чаще используют глаголы совершенного вида в действительном залоге. Женская речь включает в себя большую концентрацию эмоционально оценочной лексики, а мужская оценочная лексика чаще стилистически нейтральна. Зачастую женщины склонны к интенсификации прежде всего положительной оценки. Мужчины более выражено используют отрицательную оценку, включая стилистически сниженную, бранную лексику и инвективы; они гораздо чаще употребляют сленговые слова и выражения, а также нелитературную. Мужская письменная речь:

1. использование армейского и тюремного жаргона;

2. частое употребление вводных слов, особенно имеющих значение констатации: очевидно, несомненно, конечно;

3. употребление большого количества абстрактных существительных;

4. употребление при передаче эмоционального состояния или оценки предмета или явления слов с наименьшей эмоциональной индексацией; однообразие лексических приемов при передаче эмоций;

5. сочетания официально и эмоционально маркированной лексики при обращении к родным и близким людям;

6. использование газетно-публицистических клише;

7. употребление нецензурных слов как вводных (Любовь, *****, нашел) и однообразие используемых нецензурных слов, а также преобладание нецензурных инвектив и конструкций, обозначающих действия и процессы, а также преобладание глаголов активного залога и переходных;

8. несоответствие знаков препинания эмоциональному накалу речи.

Женская письменная речь:

1. наличие множества вводных слов, определений, обстоятельств, местоименных подлежащих и дополнений, а также модальных конструкций, выражающих различную степень неуверенности, предположительности, неопределенности (может быть, по-видимому, по-моему);

2. склонность к употреблению «престижных», стилистически повышенных форм, клише, книжной лексики (испытывал чувство гадливости и брезгливости; резкий разговор; силуэты подростков);

3. использование коннотативно нейтральных слов и выражений, эвфемизмов (нецензурно выражался вместо матерился; в нетрезвом виде вместо пьяный);

4. употребление оценочных высказываний (слов и словосочетаний) с дейктическими лексемами вместо называния лица по имени (эта сволочь; эти подонки);

5. большая образность речи при описании чувств, многообразие инвектив и их акцентуация при помощи усилительных частиц, наречий и прилагательных. 
При анализе интонации мужских и женских голосов обычно обращают внимание на такие явления, как речевая компетентность женщин, авангардизм или консерватизм, эмоциональность, социальный статус и социальная речь. Вопрос о речевой (интонационной) компетентности выявлялся путем сопоставления женских и мужских прочтений текста в группе одного социального статуса. Образованные женщины в такой же степени владеют интонационной нормой для чтения, как и мужчины. Существенное отличие, тем не менее, наблюдается, в частности, для нисходящих тонов. И мужчины, и женщины проявляют тенденцию к повышенной частотности нисходящих тонов. Однако женщины «опережают» мужчин в этом направлении, увеличивая частотность на 21,2\% (против 13,4\%). Следовательно, предполагается, что женщины проявляют особую чуткость в сфере современных произносительных тенденций при употреблении тонов, становясь действительно проводниками произносительных инноваций. Многими лингвистами, среди которых В.В. Потапов подчеркивается, что одной из характерных черт женской речи является использование оценочных прилагательных. Мужчина если и использует оценочные прилагательные, то скорее те из них, которые определяют количественные и параметрические отношения. В заключение данного исследования следует отметить перспективность дальнейших кросскультурных, сопоставительных исследований

\section{Выводы}

Проанализировав материал можно сказать, гендер адресата влияет на структуру высказывания, ее эмоциональную окраску, композицию самого общения.

Именно в диалогах и репликах обиходного общения находит свое отражение психологизм нашей речи. Проявляется характер, симпатии, недовольство, весь спектр качеств человеческого характера. По манере общения, стилю и лексическому запасу о человеке можно сказать многое: где родился и вырос, в какой семье воспитывался, какой социальный статус имеет, а также род занятий, предпочтения в жизни, интересы и многое другое.

\section{ЛИТЕРАТУРА}

1. Назарова Е.Д. Реклама для него или для нее? / Е.Д. Назарова // Русская речь. - 2009, №1. - С.70-74.

2. Формановская Н.И. Речевое общение. Коммуникативно- прогматический подход., / Русский язык. -2002. - С174

3. Назарова Е.Д. Гендерный стереотип как средство адресации рекламного текста [Текст] / Е.Д. Назарова // Русский язык за рубежом. - 2009 , №1.

4. Назарова Е.Д. $О 6$ изучении дискурса в гендерных исследованиях / Е.Д. Назарова // Человек. Язык. Культура (памяти профессора Н.В. Черемисиной). Материалы Международной научно-практической конференции 4-6 ноября 2002 г., МПГУ.- М.: МПГУ, 2002. - С.136.

5. Назарова Е.Д. 0 гендерных исследованиях в лингвистике / Е.Д. Назарова // Пушкинские чтения - 2002: Материалы конференции. - М.: Гос. ИРЯ им. А.С. Пушкина, 2003. - С.216-217.

6. Назарова Е.Д. 0 гендерных предпочтениях в речевых тактиках начала диалога / Е.Д. Назарова // Речевая коммуникация на современном этапе: социальные, научно-практические и дидактические проблемы. Материалы международной научно-методической конференции 5-7 апреля 2006. М: ГОУВпо «МГУС», 2006. - 4.2. - С. 91-95.

( К Кривошеева Елена Николаевна (krivosheeva.elena.1969@mail.ru).

Журнал «Современная наука: актуальные проблемы теории и практики» 